\title{
LA DIFÍCIL CONFECCIÓN DEL ENCASILLADO EN LA RESTAURACIÓN
}

\author{
THE DIFFICULT TASK OF MAKING THE «ENCASILLADO» \\ DURING THE SPANISH RESTORATION
}

Alejandro Martínez Relanzón* Universidad Católica de Valencia, España

\begin{abstract}
RESUMEN: Desde el restablecimiento del sufragio universal masculino en 1890 hasta las elecciones a de 1923, las últimas de Diputados a Cortes de la Restauración, los partidos políticos dominantes en la España de la época continuaron asegurándose el reparto del poder por medio del encasillado. La práctica, aunque no era nueva, se había institucionalizado de tal manera al principio de este periodo, que su confección prácticamente reflejaba el futuro retrato del parlamento antes incluso de los comicios. Aquellos cuyo nombre apareciera en las listas del gobierno representarían con probabilidad a los distritos que, en teoría, les habrían respaldado. Ahora bien, ¿eran los candidatos encasillados aquellos a los que apoyaban y escogían las fuerzas políticas y sociales locales, y por tanto los legítimos representantes del distrito, o no? Basado el análisis en la provincial de Valencia, se procura aquí dilucidar esta cuestión de vital importancia, por cuanto que su respuesta refleja la extensión de la representatividad del parlamento durante la Restauración.

PALABRAS CLAVE: Encasillado, representatividad, Restauración, elecciones, España, Valencia.

ABSTRACT: Ever since the reintroduction of the universal male suffrage in 1890 until the 1923 election, the last one of the Restoration, the ruling political parties in Spain repeatedly used a practice called "encasillado». This gave them the control of the Parliament by assigning the seats to certain candidates even before the election had taken place. Although the «encasillado» was not $n e w$, it became the only way in which governments arranged the elections. The question here is to know whether the governmental candidates were chosen based upon their connection with the party or, on the contrary, upon their influence in the district. Thus, this article attempts to clarify this question basing its study in the province of Valencia. The matter is essential, since it will indicate up to what extent the Parliament in Spain during the Restoration was representative of the people's will.
\end{abstract}

KEYWORDS: Encasillado, representativity, Restoration, elections, Spain, Valencia.

* Correspondencia a: Alejandro Martínez Relanzón. Universidad Católica de Valencia. Facultad de Filosofía, Letras y Humanidades. Departamento de Humanidades. Sede de Santa Úrsula, Despacho 20010, calle de Guillem de Castro, 96, 46001 Valencia (Spain) - alejandrorelanzon@yahoo.com - https://orcid.org/0000-0003-2863-9503

Cómo citar: Martínez Relanzón, Alejandro (2020). «La difícil confección del encasillado en la Restauración»; Historia Contemporánea, 64, 775-808. (https://doi.org/10.1387/hc.20614).

Recibido: 26 febrero, 2019; aceptado: 29 julio, 2019.

ISSN 1130-2402 - elSSN 2340-0277 / C 2020 UPV/EHU

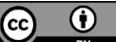

Esta obra está bajo una licencia

Creative Commons Atribución 4.0 Internacional 
«...ha quedado terminado el arreglo en esa provincia de la siguiente forma; Capital, la persona que se designará por el partido. Alcira. Sr. Pittaluga; Albaida, Torrefiel; Chelva, un amigo del Sr. Alba; Chiva, Sr. Berenguer; Enguera, Sr. Hernández Lázaro; Gandía, albista; Játiva, Rubio; Liria, Izquierdo; Requena, García Pardo; Sagunto, García del Moral; Sueca, albista; Torrente, Campos». Telegrama del Ministro Gobernación al Gobernador Civil, 16 de enero de 1923. AHN, Ministerio de Interior, Leg 29-A, carpeta 4.

Mucho se ha escrito sobre los comicios en España durante la Restauración. De hecho, existen variados y excelentes estudios sobre la práctica electoral de aquella época ${ }^{1}$. Con todo, las explicaciones sobre la práctica del encasillado no difieren en mucho entre ellas por cuanto que se ha analizado generalmente con una perspectiva «desde arriba». Es por ello que resultaba necesario un estudio profundo e individualizado de este fenómeno «desde abajo», que pudiese aportar conclusiones diversas. Las fuentes han sido determinantes para ello, ya que, en contra de lo señalado por Tusell, que afirmaba que «la labor de realización del encasillado no deja rastro escrito ${ }^{2}$, la documentación encontrada al respecto es muy abundante. En este sentido, en el presente estudio se trabaja de manera consciente justo al revés de lo que suele ser habitual: no de arriba abajo, sino de abajo a arriba. Se parte pues de un análisis exhaustivo de la práctica política de una provincia de tan acusados contrastes como Valencia, donde además se produjo la penetración en el sistema de fuerzas políticas contrarias al turnismo, como los carlistas y republicanos, y la consolidación de candidatos locales, dificultando ambos factores la dinámica del encasillado. Todo ello permite que sus resultados puedan ser extrapolados al resto del país. Para todo ello ha sido necesario un examen de la confección del encasillado en función de la correspondencia cruzada entre los propios actores, es decir, los aspirantes, los candidatos, los jefes provinciales de partido, el Gobernador, y el Ministro de Gobernación. De este modo se podrá determinar si el encasillado respondía a la imposición gubernativa, o si por el contrario reflejaba también la correlación de fuerzas de cada partido o candidato.

${ }^{1}$ Destacan los estudios de Varela Ortega, Dardé, Arranz, Tusell, Garrido, Cruz, Yanini, Veiga Aloso o Forner entre otros muchos.

2 TuSELL (1976: 28). 


\section{Su confección}

Se entiende por encasillado la lista de candidatos del Gobierno a quienes este designaba distrito electoral en los comicios para Diputados a Cortes. Pese a que se lo asocia invariablemente con la Restauración, no era propio solo de esta época. Como tal, ya existía antes de que Romero Robledo lo confeccionase allá por 1876. La novedad a partir de ese año consistió en que dejó de servir únicamente a los intereses del partido gubernamental para ser acordado entre los grandes partidos. No hay que olvidar que el encasillado era la consecuencia del pacto político entre los partidos del régimen ${ }^{3}$.

Sobre la base de este acuerdo, el partido llamado al poder se comprometía a respetar los compromisos fijados y reservar un cierto porcentaje de escaños a la oposición dinástica, que hasta la fragmentación de los dos grandes partidos rondaba entre el quince y el treinta por ciento del total. El reparto alcanzó no solo a los candidatos monárquicos, sino también a los partidos contrarios a la propia Monarquía, como los republicanos y los carlistas, a los que se les asignaban algunos escaños en la Cámara. A estos últimos, el Gobierno podía exigirle a cambio algún tipo de compensación. Por ejemplo, un diputado republicano podía ofrecer en contrapartida una postura moderada y flexible con la Monarquía o, si era republicano radical como en el caso de Alejandro Lerroux, una oposición desde el Parlamento al catalanismo ${ }^{4}$.

Con todo, por mucho que el Gobierno intercediese por un determinado candidato o grupo en pro de la representatividad de todos, debía de tener en cuenta tanto la correlación previa de fuerzas electorales como la de los notables donde los hubiera, ya que estos últimos ejercían una importante influencia sobre muchos electores. No hay que olvidar que el encasillado era un pacto muchas veces tácito, por lo que a veces funcionaba y a veces no.

Es precisamente esta práctica del encasillado lo que diferenciaba a España del resto de las naciones occidentales de su entorno. Ya que única-

${ }^{3}$ En este sentido, son clarificadoras las palabras pronunciadas en un banquete por el Vicepresidente de la comisión provincial del partido conservador de Alicante Elier Manero, sobre la necesidad de retraerse y apoyar a sus rivales por responsabilidad política «... no obstante haber transcurrido pocos días desde que nuestro jefe D. Eduardo Dato dejó paso al Partido Liberal para que dirija este los destinos del país, no obstante haberse alejado por mucho tiempo la posibilidad de que nuestros amigos disfruten las excelencias del poder... que entregamos ya a los liberales... el Partido Liberal conservador les ayudará leal y desinteresadamente en la empresa que tan temerariamente han querido asumir antes de tiempo». Sin AUTOR, 1915, p. 8.

${ }_{4}^{4}$ Lerroux y el encasillado, en Tusell, 1976, p. 31. 
mente en este país los partidos mayoritarios pactaban los resultados antes de las elecciones. Esto supuso por una parte un retraso en la plena democratización del país, pero por otra una relativa estabilidad y gobernabilidad.

La confección del encasillado no era tarea fácil. De hecho, tras el análisis de toda la documentación ministerial relativa a su elaboración en la provincia de Valencia, sorprende como los ministros pudieron gestionar todos y cada uno de los encasillados provinciales, tal y como parece que fue el caso. Gumersindo de Azcárate afirmó al respecto que la primera condición de un buen Ministro de la Gobernación era que poseyera arte y habilidad para hacer elecciones, sin lo cual no tendría ni el amor de sus amigos, ni el respeto de los contrarios ${ }^{5}$. No andaba desencaminado el ilustre repúblico, pues era de la labor del ministro de la que en última instancia dependía el éxito del Gobierno en las elecciones. Como primer paso, el propio ministro negociaba con los líderes de las facciones políticas rivales más representativas su cuota parlamentaria como grupo de oposición. Durante este primer esbozo de reparto se reservaban ciertos distritos a determinadas facciones políticas según sus zonas de influencia. De hecho, en los territorios del antiguo Reino de Valencia fueron muy comentados los escaños reservados en Castellón a los tetuanistas, y en Alicante a los demócratas canalejistas (especialmente en Alcoy) ${ }^{6}$. En la provincia de Valencia se reservó a los canalejistas en más de una ocasión los distritos de Gandía (Gutiérrez Mas) y Requena (García Berlanga) ${ }^{7}$. Diferente suerte corrían generalmente las fuerzas opuestas al nuevo sistema. Algunas de ellas como republicanos o carlistas quedaron marginadas, y otras como las socialistas, totalmente excluidas. En Valencia, al igual que en el resto del país, los gobernadores incluyeron en el encasillado en determinadas ocasiones a los dos primeros. En 1896 el Gobernador trabajó junto a Sapiña y el notable local Bau en la candidatura por Sueca del tradicionalista Ibáñez de Lara ${ }^{8}$, y en 1923, el favorecido por el Ministerio en Alcira fue el republicano reformista Pittaluga.

5 Gumersindo de Azcárate, Cit. en GutiérReZ y Zurita, 2001, 315.

${ }^{6}$ Canalejas fue diputado por el distrito de Alcoy consecutivamente en los comicios de 1891, 1893, 1896, 1898, 1899, 1901, 1903, 1905, 1907 y 1910. Fuente: ACD.

${ }^{7}$ En las elecciones conservadoras de 1907 con Maura en la Presidencia del Consejo de Ministros, el propio Canalejas logró que el Ministro La Cierva se comprometiera a asegurarle los distritos de Alcoy y Requena en los comicios de 1907. GutiérREZ y ZuRITA, 2000, 336.

8 YANINI, 1984b, 63. 
Pero antes de elaborar cualquier combinación, el Ministro de Gobernación se informaba de la situación político-electoral de cada provincia. El modo que Santiago Alba empleó para ello en 1916 fue un telegrama en donde pedía a sus gobernadores un informe de la situación electoral en cada una de las demarcaciones, lo que podría considerarse como el primer «esbozo del encasillado».

«Sírvase V.S. después de conferenciar con las personas más significativas que pueden suministrarle datos del asunto y de conocer también la opinión de los Diputados de los respectivos distritos, enviarme antes de fin de mes por correo o por telégrafo, nota que exprese el número y nombre de los distritos de esa provincia a quienes toca acudir a la próxima elección de diputados provinciales, distribución de las fuerzas políticas en esa diputación, candidatos que aspiran a la reelección con su filiación respectiva, nuevas aspiraciones de que tenga noticia y fuerzas electorales que atribuya a cada una de ellas, combinaciones o pactos de que esté informado entre las fuerzas liberales y las conservadores y juicio de V.S. sobre los resultados que en esa provincia fuere posible obtener en la elección próxima para los candidatos adictos y situación en que quedaría la diputación después del cálculo de probabilidades que V.S. haga del resultado que podría esperarse de la elección.»9

El Gobernador se apoyaba, para realizar este informe, en las personas más influyentes en la política provincial: diputados, jefe del partido dinástico rival, notables locales, y especialmente en el jefe provincial de su propio partido. Era este último quien elegía y redistribuía los candidatos entre los distritos de la provincia, tarea que durante los gobiernos liberales de la primera parte del periodo correspondió en Valencia a Ruiz Capdepón. El Gobernador, tras recabar la información requerida, elaboraba un informe detallando la situación política de los distritos, y proponía candidatos en casi todos los distritos. En la circunscripción de Valencia solo se proponía uno ante la dificultad que entrañaba para los dinásticos aspirar a más de una de las tres actas. Esta lista era un «borrador» del encasillado provincial.

${ }^{9}$ Circular Telegrama del Ministro de Gobernación a todos los gobernadores civiles. 23 de enero de 1916. AHN, Ministerio de Interior, Leg.27-A, núm. 6. Al igual que Alba, Eduardo Dato había solicitado el mismo informe a los gobernadores a la hora de diseñar el encasillado de 1899: «Ruego a V.I. me digan por telegrama cifrado los nombres de los candidatos cuyo triunfo considere probable en cada distrito y su filiación política y cuanto considere necesario para formar juicio del estado de la elección». Telegrama del Ministro de Gobernación a los gobernadores civiles. 5 de abril de 1899. AHN, Ministerio del Interior, 19A, Exp. 13. 


\section{Cuadro 1}

Relación de gobernadores civiles de Valencia, ministros y presidentes durante las elecciones 1890-1923

\begin{tabular}{|c|c|c|c|}
\hline Elecciones & $\begin{array}{c}\text { Gobernador Civil } \\
\text { de Valencia }\end{array}$ & $\begin{array}{c}\text { Ministro } \\
\text { de Gobernación }\end{array}$ & $\begin{array}{l}\text { Presidente del Consejo } \\
\text { de Ministros }\end{array}$ \\
\hline $1 / 2 / 1891$ & $\begin{array}{l}\text { Nicolás María de } \\
\text { Ojesto }\end{array}$ & Francisco Silvela & Antonio Cánovas \\
\hline $5 / 3 / 1893$ & Rafael Sarthou & $\begin{array}{l}\text { Venancio González y } \\
\text { Fernández }\end{array}$ & Práxedes Mateo Sagasta \\
\hline $12 / 4 / 1896$ & Eduardo de Hinojosa & $\begin{array}{l}\text { Fernando Cos-Gayón } \\
\text { y Pons }\end{array}$ & Antonio Cánovas \\
\hline $27 / 3 / 1898$ & Francisco Ballesteros & $\begin{array}{l}\text { Trinitario Ruiz } \\
\text { Capdepón }\end{array}$ & Práxedes Mateo Sagasta \\
\hline $16 / 4 / 1899$ & Conde de San Simón & Eduardo Dato & Francisco Silvela \\
\hline 19/05/1901 & Lorenzo Moncada & Segismundo Moret & Práxedes Mateo Sagasta \\
\hline 25/04/1903 & $\begin{array}{l}\text { José Martos O’Neale } \\
\text { (dimitido). Sustituido } \\
\text { por Alfonso González }\end{array}$ & Antonio Maura & Francisco Silvela \\
\hline $10 / 09 / 1905$ & Luis Albarado & Manuel García Prieto & Eugenio Montero Ríos \\
\hline 21/04/1907 & Genaro Pérez Moso & Juan de la Cierva & Antonio Maura \\
\hline 08/05/1910 & Joaquín Moreno & $\begin{array}{l}\text { Fernando Merino } \\
\text { Villarino }\end{array}$ & José Canalejas \\
\hline 08/03/1914 & José Centaño & José Sánchez Guerra & Eduardo Dato \\
\hline 09/04/1916 & Leopoldo Cortinas & Santiago Alba & Conde de Romanones \\
\hline 24/02/1918 & Juan Sánchez Anido & $\begin{array}{l}\text { José Bahamonte } \\
\text { (Vizconde de } \\
\text { Matamala) }\end{array}$ & Manuel García Prieto \\
\hline 01/06/1919 & Rafael Durán & Antonio Goicoechea & Antonio Maura \\
\hline $19 / 12 / 1920$ & Salvador Muñoz Pérez & Gabino Bugallal & Eduardo Dato \\
\hline 29/04/1923 & $\begin{array}{l}\text { Xavier Cabello } \\
\text { Lapiedra }\end{array}$ & Martín Rosales Martel & Manuel García Prieto \\
\hline
\end{tabular}

Fuente: elaboración propia a partir de los datos del ACD. 
Los gobernadores disponían en la mayoría de las ocasiones de más aspirantes a candidatos que distritos. Sobre esa base, se procuraba elegir a aquellos que mayores probabilidades de triunfo ofrecieran y a la vez se trataba de evitar que aquellos desplazados acudieran a la lucha. Tanta importancia revestía esta tarea, que de ella dependía en última instancia el éxito del encasillado. De hecho, en caso de no resultar satisfactorios los resultados electorales para el Gobierno, los propios gobernadores podían llegar a ofrecer su renuncia al Presidente del Consejo $^{10}$.

En la provincia de Valencia, la existencia de un acuerdo verbal entre las directivas de los partidos de turno facilitó enormemente la negociación entre el Gobierno y el partido en la oposición. Antes de adjudicar distritos, el Gobernador procuraba consensuar los nombres de los aspirantes con el líder provincial de su partido. Este último, al actuar de canal de las aspiraciones individuales y tener una relación más directa con los notables locales que el propio Gobernador, adquirió tal protagonismo en la elección y distribución de los nombres encasillados, que su criterio llegó en ocasiones a prevalecer sobre la voluntad del propio Gobierno. Entre ambos procuraron confeccionar un encasillado que, ajustándose a las directrices nacionales, satisficiera en la medida de lo posible las diversas aspiraciones locales y proporcionara al Gobierno un resultado electoral satisfactorio. También entraba en las discusiones el líder provincial de oposición dinástica, que en caso de no estar de acuerdo con la cuota ofrecida podía presionar para que se le ofreciera, sino algún distrito más, al menos alguna que otra senaduría. Un ejemplo de ello lo tenemos en el «farol» lanzado por el Marqués de Cáceres, líder provincial del Partido Conservador en 1916, que tras obtener únicamente un distrito en el encasillado de ese año amenazó con lucha si no se le concedía alguno más: «...habiendo recibido órdenes terminantes del Sr. Dato para que los conservadores luchen por todos los distritos de la provincia por haber rotos sus relaciones electorales en las mismas con el Gobierno» ${ }^{11}$. Bastaba generalmente el ofrecimiento de alguna senaduría adicional $\mathrm{u}$ otro puesto de categoría en la administración para retirar la amenaza. El mismo ministro,

10 Telegrama del Ministro de Gobernación al Gobernador de Valencia, 12 de octubre de 1905. AHN, Ministerio del Interior, Leg. 22, núm. 6.

11 Telegrama del Gobernador de Valencia al Ministro de Gobernación, 23 de marzo de 1916. AHN, Ministerio de Interior, Leg.27-A, núm. 11. 
consciente de ello, podía autorizar al Gobernador para la adjudicación de tales prebendas ${ }^{12}$.

Ahora bien, la victoria de los candidatos encasillados no era el único objetivo del Gobernador, o al menos no debía de serlo. Como se ha indicado, la Restauración procuraba el consenso, el pacto, la alternancia pacífica. Las luchas eran inevitables, pero era responsabilidad del Gobernador intentar evitarlas, y, sobre todo, prescindir en lo posible del uso coercitivo de su poder por los perjuicios que este podía provocar. En este sentido, ante el anuncio de lucha en un determinado distrito el Gobernador procuraba llegar a algún tipo de acuerdo con el candidato de la oposición. Precisamente, esto fue lo que hizo el Gobernador Cortinas cuando en 1916 convenció al líder de los conservadores valencianos con una senaduría para que los suyos retiraran tres candidaturas en distritos ya adjudicados a los liberales ${ }^{13}$. Fue también lo que procuró su sucesor en el cargo Rafael Durán, cuando en la campaña de 1919 propuso un candidato de consenso en el distrito de Játiva para evitar la lucha entre las dos facciones allá violentamente enfrentadas: «Manifiesta el Sr. Rubio, que frente a la candidatura del Marqués de Vivel presentará la suya luchando con toda decisión. En cambio, si fuese candidato adicto el Sr. Canals no lucharía prestándole su apoyo» ${ }^{14}$.

Otra de las prácticas empleadas para evitar la lucha fue la distribución de cargos municipales entre las redes clientelares en pugna. Para ello, las elecciones municipales brindaban la oportunidad de adjudicar puestos en la administración a los amigos de un determinado grupo político. Este fue el arreglo al que se llegó en las últimas elecciones del periodo en Játiva, distrito en donde todavía coleaba la rivalidad entre las dos facciones

12 En la campaña de 1916, el Ministro Alba autorizó al Gobernador a ofrecer una senaduría adicional a los conservadores para que estos no presentaran lucha en la provincia. Telegrama del Ministro de Gobernación al Gobernador de Valencia, 24 de marzo de 1916. AHN, Ministerio de Interior, Leg.27-A, núm. 11.

13 Telegrama del Gobernador de Valencia al Ministro de Gobernación, 17 de marzo de 1916. AHN, Ministerio de Interior, Leg.27-A, núm. 11.

14 Telegrama del Gobernador Civil al Ministro Gobernación, 22 de agosto de 1919. AHN, Ministerio de Interior, Leg 28-A, carpeta 3. La respuesta del Gobierno retirando la candidatura de Vivel y apoyando la propuesta por Castro ejemplifica hasta qué punto se pretendía evitar la lucha en el distrito: «Estimo que el ofrecimiento es serio y formal y posible art. 29; y caso de que algún elemento lo perturbase, un triunfo seguro. En su virtud me parece conveniente que el Gobierno retire ya la candidatura de Vivel quien de luchar tendría los inconvenientes que expuse a V.E.». Telegrama del Gobernador Civil al Ministro Gobernación, 31 de agosto de 1919. AHN, Ministerio de Interior, Leg 28-A, carpeta 3. 
liberales enfrentadas. El Gobierno, con miras a evitar la lucha, repartió entre los amigos de Castro la mitad de las concejalías de las localidades más importantes del distrito. Gracias a lo cual su rival Rubio pudo asegurarse el acta sin competencia a través del artículo 29 de la Ley Electoral de $1907^{15}$.

Precisamente para evitar la intervención en las elecciones en los casos en que los dos candidatos en pugna fueran del partido gobernante, el Gobernador llegaba a invertir en plena campaña su apoyo con tal de que el candidato triunfante fuera el encasillado. En función de ello, si el candidato ministerial partía en clara inferioridad, el Gobierno podía llegar a declararse neutral a mitad de campaña dejando el camino expedito al candidato hasta entonces opositor. En la mayoría de ocasiones la consecuencia más inmediata de este cambio de escenario era la retirada del candidato despojado de ayuda y por tanto la concurrencia en solitario del candidato «rival». Fue esta la dicotomía en la que se vieron algunos candidatos que acabaron optando por la retirada, como Pereyra en Requena en 1905, e Ibáñez Rizo en Gandía en $1923^{16}$.

Este pragmatismo se extendía también a la elección de los candidatos, ya que en distritos movilizados o con fuerte influencia política local de fuerzas de oposición, los candidatos se consensuaban, no ya con el resto de candidatos, sino con los propios notables del lugar. Un ejemplo de ello se encuentra en los comicios de 1903 en los cuales el Gobernador de Valencia, ante el poder del republicano Escuder en Chiva, buscó un candidato de consenso con los grupos locales más influyentes: «En Chiva fuerte partida republicana que dirige Escuder, no permiten en modo alguno imponer candidato, que ha de ser a gusto de los caciques locales, pues de otro modo triunfaría el republicano» ${ }^{17}$.

15 Telegrama del Ministro Gobernación al Gobernador Civil, 3 de marzo de 1923. AHN, Ministerio de Interior, Leg 29-A, carpeta 4. La mencionada ley electoral, en TuSELL, 1970.

${ }^{16}$ La retirada de Ibáñez Rizo se debió tanto al apoyo de los comités del partido al candidato rival, como al frente abierto contra él por los ciervistas, albistas y disidentes liberales del distrito, que habían coincidido en apoyar al liberal rival: «Presidiendo representaciones de todos los partidos políticos y fuerzas vivas del distrito Gandía, hemos proclamado candidato para diputados, jefe de las fuerzas albistas, Melchor Román; estamos dispuestos a no tolerar ningún encasillado ni atropellos Gobierno para hacer creer que tiene sufragios Ibáñez Rizo, que abandona la capital». Las Provincias, 15 de abril de 1923.

17 Telegrama del Gobernador de Valencia al Ministro de Gobernación: Valencia, 25 de agosto de 1903. Cit. en Castillo, 1999, 60. 
Sobre los casos en los que no existía consenso entre dos o más grupos locales para la designación del candidato, la decisión se remitía al ministro. No se han encontrado por el contrario, documentos en los que el Presidente del Consejo interfiriera en la confección del encasillado. Únicamente se ha localizado un telegrama en que el Sagasta rechaza inmiscuirse en estos asuntos y pide al Gobernador que sean los líderes provinciales los que determinen los candidatos, y otro dirigido a Romanones en el que se le pide que tome partido por uno de los dos aspirantes pero que no tiene respuesta ${ }^{18}$.

De las cartas y telegramas analizados, se concluye que la última palabra la tomaba o el ministro o el jefe provincial del partido, dependiendo de la autoridad de cada uno y del contexto particular. Estando Maura en Gobernación en 1903, era él quien decidía. De hecho, ese año el líder conservador determinó que fuese Juan Pardo y no Prats, el candidato encasillado por Liria.

«Recibo su grata carta de 28 de Febrero último, en la que con tanto interés se sirve recomendarme á D. Juan José Pardo, para que á ser posible, figure en la combinación general que aquí se forme, como candidato adicto á Diputado á Cortes; y deseoso como siembre de complacerle, he trascrito en el acto su citada carta al amigo Sr. Lázaro, para que vea si hay medio de satisfacer los deseos del mencionado Sr. Pardo.»19

No obstante, el criterio del Gobierno no siempre se imponía. En 1916 el líder provincial, el Senador Ramón Castro, no cedió ante Santiago Alba, y se negó a variar el encasillado para abrir un hueco a última hora a un candidato que el Gobierno poco menos que exigía encasillar en la provincia. La petición del ministro comenzó con una sugerencia. Alba le pidió al Gobernador (que actuaba de intermediario) que le recordara a Castro los favores que le había hecho nombrando alcaldes sugeridos por él, y que le preguntara por la posibilidad de encasillar a Prat de Bucelli, Conde de Berbedel. A ello Castro le respondió (también a través del Gobernador) con pesimismo. Con todo, le ofreció dos opciones. Una era encasillarlo en

18 Sagasta, en Telegrama del Ministro al Gobernador, 24 de marzo de 1899. AHN. FC-M. Interior A.19A, Exp. 13. El mensaje dirigido a Romanones, en Telegrama fonema del Presidente Círculo Liberal a Romanones, sin fecha (presumiblemente 1916). Real Academia de la $\mathrm{H}^{\mathrm{a}}$. Archivo Romanones, Leg. 51, n.10.

${ }_{19}$ Carta del Gobernador Pérez Moso a Maura. 2 de marzo de 1907. AM, Legajo 159, carpeta 12 . 
el distrito de Játiva, donde no tendría posibilidad alguna de triunfar. Y la otra enviarlo a Alicante y desentenderse así de él. Esta negativa se debía principalmente a la condición de opositor del candidato, ya que adjudicarle un distrito suponía desplazar a un miembro del propio partido por la provincia a favor de un rival. Con el fin de facilitar las cosas, el ministro propuso que se le encasillase por uno de los dos distritos en los que sus candidatos no habían sido nunca elegidos diputados (Gandía donde concurría Ibáñez Rizo o Sueca por donde lo hacía el Marqués de Castellfort). Pero pese la presión, el líder provincial mostró firmeza y rechazó cambiar las candidaturas propuestas. Propuso, como mal menor, ofrecer al Conde, «la senaduría que aquí siempre se destinó a las derechas...». No satisfecho, el ministro insistió todavía una vez más invocando la voluntad del mismo presidente. Sin embargo, Castro mantuvo la misma determinación: «no es en modo alguno viable ni posible la alteración que se le ha transmitido en el encasillado por esta provincia. No se trata de un simple capricho ni de la resultante de un apasionado empeño, sino del producto de serias observaciones...». Tras este telegrama Alba no tuvo más remedio que aceptar la situación, no sin antes dejar patente su disgusto con el Senador $^{20}$. En definitiva, este episodio muestra la importancia que los comités provinciales y locales habían adquirido en los últimos años en la confección del encasillado, lo que da fe de la cuota importante de poder decisorio provincial existente frente a las proposiciones/imposiciones ministeriales.

Con todo, la capacidad de maniobra de la dirección provincial dependía también de su cohesión interna. En los momentos en que el partido no tenía un jefe provincial indiscutido, era el Gobierno el que adquiría protagonismo. En los comicios de 1916, el Gobernador trató de imponer su criterio ante la falta de acuerdo de los dos notables que se disputaban el control del partido conservador: el Marqués de Cáceres y Hernández Lázaro, empeñados a poner cada uno a su propio candidato: «no ha sido posible conseguir que el Marqués de Cáceres y Hernández Lázaro se pongan de acuerdo respecto de cual de los dos ha de representar el distrito reservado á los conservadores $»^{21}$.

${ }^{20}$ El intento de encasillar al Conde de Berbedell en la provincia de Valencia, en los telegramas cruzados entre Castro y Alba del 1 al 16 de marzo de 1916. AHN, Leg.27-A, núm. 11.

21 Telegrama del Gobernador al Ministro de Gobernación, 2 de abril de 1916. AHN, Ministerio de Interior, Leg.27-A, núm. 6. 
Por otro lado, y como consecuencia de esta política de abrir puestos a la oposición, diversos grupos locales del partido en el poder se vieron damnificados por su propio partido en estos distritos reservados a candidatos rivales, lo en expresión de la época se llamaba «abrir un hueco en el encasillado». La respuesta de los aspirantes afectados resulta difícil de determinar. No obstante, en los telegramas se han encontrado tres diferentes reacciones que bien pueden dar una idea de ello. La primera es la de resignarse y aceptar el pacto, que es lo que hizo Carlos Testor en 1916 cuando Alba encasilló a un conservador por el distrito de Enguera ${ }^{22}$. La segunda es la de pedir alguna compensación por quedar desplazado, que es lo que hizo José Herrero tras quedar fuera del encasillado de Requena en 1893. Y por último, la de rebelarse y presentar lucha como candidato de oposición, que es lo que hizo Ramón Castro en los comicios de 1898.

Sin pretender entrar a analizar todas y cada una de las elecciones del periodo, sí que es conveniente, aunque sea como muestra para la correcta comprensión del encasillado, detenerse en su confección en la provincia. La llevada a cabo en 1905 es una buena muestra. Los comicios de aquel año, que fueron convocados por un gabinete liberal en plena división interna entre los seguidores de Montero Ríos, Canalejas y Moret, presentaron en la provincia de Valencia dos de las situaciones que en última instancia provocaban la derrota de alguno de los candidatos encasillados. Por un lado, un gran apoyo republicano en la capital, y por otro, la presencia de varias candidaturas rebeldes.

Con un mes de antelación a las elecciones se comenzaron a trazar los primeros esbozos del encasillado en la provincia. Las negociaciones se llevaron a cabo a diferentes bandas, aunque fue el Gobernador Luis Alvarado el que llevó la voz cantante. Tras varios cambios en los nombres de los candidatos encasillados se llegó a un principio de acuerdo por el cual se adjudicaría a los liberales diez distritos rurales, abriendo así dos puestos en la provincia: uno para los conservadores y otro para los romeristas. En la capital, dada la dificultad de obtener acta, se prescindió de dos de los tres puestos. El que quedó se reservó a Tomás Trénor, una de las per-

${ }^{22}$ El liberal de este distrito reservado a la oposición conservadora, pregunta al Gobernador si hay posibilidad de presentare «El Sr. Testor me escribe repetidamente diciendo que en caso de que se establezca alguna modificación en el distrito de Enguera, se cuente con él... Le comento diciéndole que nada nuevo hay en la combinación electoral acordada...». Telegrama del Gobernador al Ministro de Gobernación, 5 de abril de 1916. AHN, Leg.27-A, núm. 11. 
sonas más influyentes y respetadas de la ciudad, que con los años obtendría el título de Marqués del Turia. Sin embargo, el liberal se retiró tres días antes de los comicios tras comprobar que la Liga Católica en lugar de apoyarle a él lo hacía al candidato carlista, lo que prácticamente le dejaba sin opciones de victoria ${ }^{23}$.

En el resto de la provincia, el Gobernador tuvo que negociar las candidaturas en distritos en donde candidatos no apoyados por el Gobierno amenazaban con lucha si no se les brindaba el apoyo ministerial. Uno de ellos era el poderoso Manuel Iranzo, a quien el Gobernador en principio quiso dejar fuera a pesar de los intentos del propio aspirante: «... Sr. Iranzo se presenta en el despacho protestando de su exclusión. Recurre por telégrafo á V.E. y al Sr. Canalejas; pero ruego no le atienda, pues destruiría toda la combinación ${ }^{24}$. Otro caso se dio en el distrito de Liria. Allá, el Gobernador pidió a Izquierdo, candidato con más fuerza del distrito, que presentara su candidatura por Chiva para así dejar el distrito libre al candidato cunero romerista Bores. Pero el acuerdo se vio bloqueado por Francisco Escutia, candidato natural de los liberales por Chiva y ahora desplazado, que no se comprometió a ofrecer su apoyo a la candidatura de Izquierdo $^{25}$. Ante esta situación, el propio Izquierdo decidió no aceptar el encasillado propuesto y presentarse como candidato de oposición en el distrito de Liria, donde contaba con mayores posibilidades que en Chiva. De este modo, el candidato liberal arruinó la combinación del encasillado, provocando el enfado de su propio jefe de partido que le desautorizó a concurrir a la lucha contra el romerista: «Habiendo presentado Teodoro Izquierdo su candidatura en Liria contra lo convenido por mi... me veo obligado á desautorizarla comunicando resolución a Sapiña» ${ }^{26}$. Finalmente, y ante la situación planteada, el encasillado romerista terminó retirándose de la lucha, siendo sustituido consecutivamente por el romerista Jacobo Sales Reig, por el liberal Navarro Reverter y Gomis (hijo del político y varias veces ministro, Juan Navarro Reverter) y por el demócrata

23 La Correspondencia de Valencia. 7 de septiembre de 1905.

24 Telegrama del Gobernador de Valencia al Ministro de Gobernación, 2 de agosto de 1905. AHN, Ministerio del Interior, Leg. 22, núm. 6.

25 «...se veía en la imposibilidad de prestar el concurso de sus amigos al Sr. Izquierdo, pues aquellos se resistían a votar a candidato alguno que no fuese el propio Sr. Escutia». Las Provincias, 24 de agosto de 1905.

${ }^{26}$ Telegrama de Moret al Gobernador de Valencia, 26 de agosto de 1905. AHN, Ministerio de Interior, Leg 22A, carpeta 6. 
Vañó, que fue quien finalmente acudió a la lucha contra Izquierdo, que pese a los esfuerzos de Moret para que retirara candidatura acabó concurriendo y venciendo al encasillado ${ }^{27}$.

Resulta revelador que la derrota del ministerial en Liria se produzca a causa de la persistencia del Gobierno en apoyar a un candidato sin arraigo ni influencia alguna en el distrito. Este hecho revela lo arriesgado que se había vuelto designar a este tipo de candidatos, ya que además de revelarse imprudente, provocaba también críticas al nuevo Gobierno por no haber considerado la voluntad del electorado local:

«Se hablaba ayer mucho del disgusto que reinaba entre algunos miembros ministeriales por la actitud del Sr. Izquierdo presentando su candidatura por el citado distrito, pero aquí lo verdaderamente lamentable es que al hacerse el encasillado no se tuviera en cuenta la voluntad de los distritos, para el encaje de los candidatos ministeriales que con sus retiradas evidencian errores en que no debiera haberse incurrido. $Y$ lo más sensible es que el caso de Liria se repita, no solo en nuestra provincia, sino también en toda España.» ${ }^{28}$

En Játiva, el conservador Laiglesia decidió presentar batalla al candidato ministerial encasillado. Pero ante la oposición de la dirección provincial acabó retirándose. Diferente resultó la situación en el distrito de Requena, donde el encasillado fue el liberal general Pereyra (amigo del general Weyler). Sin embargo, el apoyo recibido por el candidato García Berlanga en el distrito, que se evidenciaba con los 480 interventores designados por su candidatura ${ }^{29}$, determinó que el Gobernador decidiera no intervenir en unas elecciones que de antemano parecían ya resueltas en su contra ${ }^{30}$. El quinto problema que tuvo el Gobernador se dio en el distrito de Chelva, donde el candidato natural del distrito, el también liberal Gil Roger tampoco respetó la candidatura oficial del ministerial Ibáñez y concurrió con éxito como candidato de oposición al Gobierno. Por lo que

27 «....acto rebeldía. Si insiste en ella la desautorizaré invitando á cuantos quieran seguir mis consejos y mantener la unidad del partido a quienes le nieguen su apoyo». Telegrama de Moret a Teodoro Izquierdo, 26 de agosto de 1905. AHN, Ministerio de Interior, Leg 22A, carpeta 6.

${ }^{28}$ Las Provincias, 1 de septiembre de 1905.

${ }^{29}$ Telegrama del Gobernador de Valencia al Ministro de Gobernación, 2 de septiembre de 1905. AHN, Ministerio de Interior, Leg 22A, carpeta 6.

30 Las Provincias, 5 de septiembre de 1905. 
al acabar las elecciones, encontramos que de los doce candidatos encasillados por el Gobierno en los distritos rurales de la provincia, se obtuvieron nueve. Sin embargo, y para tranquilidad del Gobierno, los tres diputados rebeldes al encasillado no lo eran a la mayoría liberal en las Cortes, ya que tanto Gil Roger como Izquierdo eran liberales y García Berlanga del Partido Liberal demócrata, por lo que se cumplió la premisa de que ser rebelde al encasillado no implicaba el ser rebelde al partido de Gobierno. No obstante, a pesar de que no peligró la mayoría liberal en el Parlamento, la valoración que hace la prensa respecto a la labor del Gobernador es de fracaso absoluto, ya que en cuatro distritos (Valencia, Requena, Liria, Chiva) los candidatos encasillados terminaron retirándose y en un uno (Chelva), este acabó siendo derrotado ${ }^{31}$. Esta «derrota» motivó que el Gobernador, como máximo responsable, pusiera a disposición del Presidente del Consejo su renuncia: «Ruego V.S. no insista en dimisión presentada; puesto que tiene la confianza del Gobierno, quien comprende las dificultades con que luchaba y escasos medios de organización que tenía» ${ }^{32}$.

\section{La postulación de los aspirantes y su designación}

Se ha visto la naturaleza y funcionamiento del encasillado, también se ha comentado como la dirección provincial del partido y los propios distritos eran los que en mayor medida proponían al Gobierno los nombres de los candidatos a ser encasillados. A continuación, se pretende analizar otro elemento importante en este proceso, que no es otro que el criterio seguido para la selección de sus actores. Para esta tarea se han analizado decenas de telegramas enviados al Ministro de Gobernación por los aspirantes, por el Gobernador de la provincia, y por los líderes provinciales del partido en el poder. De su análisis se ha concluido que la designación dependía de tres factores: respetar los compromisos contraídos, satisfacer al número máximo de clientelas y, ante todo, asegurar el triunfo del Gobierno.

En primer lugar, se observa un cambio en el modo de aproximación entre los aspirantes a candidato y el Gobierno entre los primeros y los úl-

\footnotetext{
31 Las Provincias, 11 de septiembre de 1905.

32 Telegrama del Ministro de Gobernación al Gobernador de Valencia, 12 de octubre de 1905. AHN, Ministerio del Interior, Leg. 22, núm. 6.
} 
timos comicios del periodo. Este cambio entra en relación con el aumento de la influencia del electorado y de los grupos de presión locales en la elección del candidato. De hecho, en los años de la Regencia de María Cristina los distritos eran distribuidos entre los encasillados sin que las fuerzas del aspirante en el distrito resultaran un factor esencial a tener en cuenta. En este primer periodo, los candidatos no se designaban en función de su influencia en un distrito determinado, sino por sus vínculos con los políticos valencianos más influyentes del periodo: Navarro Reverter en el Partido Conservador y Ruiz Capdepón en el Liberal. La correspondencia del aspirante Cirilo Amorós con primero de ellos es un buen ejemplo de ello:

«Leo la desgracia del Sr. Ros que deja huérfano el Distrito de Sagunto. En él tengo bastantes relaciones, y como V. tiene la llave le escribo por si quiere hacerme gentilhombre del Castillo. En buena plata, que ese Distrito me conviene, y antes que pueda $\mathrm{V}$. contraer compromisos, se lo aviso (con la más profunda reserva) por si quiere, ó cree que debo presentarme.» ${ }^{33}$

Las circunstancias fueron cambiando, y en la última década de siglo Xx la designación de candidaturas pasó, al menos en la provincia de Valencia, a depender del aparato provincial del partido. En el Partido Conservador era el directorio provincial, dominado entonces por Llorente, el encargado de elegir candidatos. Sin embargo, la designación de candidatos presentaba todavía características del pasado. De hecho, la dirección llegaba incluso a ofrecer al futuro diputado la elección de un distrito, algo difícilmente viable al final del periodo:

«Hallándose en París el señor marqués de Cáceres, recibió un telegrama de sus amigos invitándole a que presentara candidatura por cualquier distrito. El señor marqués contestó que, accediendo a los deseos que manifestaban, consentía en presentar su candidatura, dejándoles en libertad de designar el distrito, siempre que crean que exista alguna posibilidad de éxito.» ${ }^{34}$

Es en estos años cuando empieza a importar cada vez más la fuerza de la que disponían los aspirantes que se ofrecían al Gobierno. Si en un dis-

33 La carta, en Genovés , 1981, 42.

34 Las Provincias, 10 de mayo de 1899. 
trito existía más de un aspirante a candidato ministerial, el Gobernador exploraba las posibilidades de triunfo de cada uno antes de determinar a quién apoyaba de ellos. Ello motivaba que los aspirantes que solicitaban el apoyo del Gobierno le garantizaran seguridad absoluta en su elección «y sin dificultad alguna por parte cuerpo electoral» ${ }^{35}$. El hecho de apoyar al aspirante a candidato gubernamental con más posibilidades de triunfo, o al menos de no oponerse a él, motivó en numerosas ocasiones que desde el Ministerio de Gobernación se alteraran los nombres del encasillado original, lo que provocaba que los candidatos que perdían la confianza del Gobierno se retirasen.

Este pragmatismo gubernamental se muestra de manera clara en la preparación de la campaña llevada a cabo en Requena en los comicios de 1905. Allá, el candidato encasillado Pereyra se encontró con que la candidatura del también demócrata García Berlanga contaba con el importante apoyo de las organizaciones locales y de los viticultores del distrito. Estos, ante el encasillamiento del candidato rival, presionaron al Gobierno a favor de su candidatura y en contra de la rival, a la vez que le advirtieron de su determinación a luchar por el acta: «comités liberales demócratas distrito requena ratifican apoyo candidatura garcia berlanga acuerdo que fue comunicado presidente consejo mereciendo su beneplácito - cualquiera otra candidatura será apoyada por fuerzas no liberales...-» ${ }^{36}$. Tras estas primeras admoniciones, y ante la persistencia del apoyo gubernamental sobre Pereyra, el candidato «rebelde» pidió al Gobierno neutralidad en campaña. Argumentada en función del apoyo brindado por parte del partido en el distrito y a su ejemplaridad, «comprenderá v e necesidad saber si este partido demócrata de requena único en la provincia que obtuvo dos diputados provinciales va a considerársele rebelde después haber cumplido todos sus deberes... ${ }^{37}$. El Gobierno, tras percatarse de la inconveniencia de tratar de imponer su candidato ante la oposición local mostrada, optó finalmente por declararse neutral. Al fin y al cabo, García Ber-

35 Esto fue lo que hizo Iranzo, aspirante a candidato de Albaida en 1905. Telegrama de Manuel Iranzo al Ministro de Gobernación, 5 de agosto de 1905. AHN, Ministerio del Interior, Leg. 22, núm. 6.

36 Telegrama de los presidentes de los comités liberales demócratas de las principales localidades del distrito al Ministro de Gobernación, 5 de agosto de 1905. AHN, Ministerio del Interior, Leg. 22, núm. 6.

37 Telegrama de García Berlanga al Ministro de Gobernación, 8 de agosto de 1905. AHN, Ministerio del Interior, Leg. 22, núm. 6. 
langa pertenecía al mismo partido que Pereyra y su triunfo no conllevaba una alteración en la representación de los grupos políticos «encasillados». Pereyra, tras perder el apoyo del Gobierno, optó por retirarse.

El caso anterior muestra como la presión y la influencia alcanzada en ciertos distritos por las organizaciones locales en la elección de aspirantes, llegaba a determinar el nombre de los candidatos encasillados. O lo que es lo mismo, como determinados distritos «imponían» al Gobierno el candidato de su agrado en el encasillado. Esta tendencia no solo se mantuvo durante el resto del periodo, sino que aumentó. En el resto del periodo es muy común observar cómo importantes personalidades del distrito presionan al Gobierno en esa dirección. De hecho, hubo casos, como en Gandía en los comicios de 1916, en los que la campaña para reclamar al Gobierno que proclame como candidato suyo a un aspirante concreto, involucró a alcaldes, concejales, militantes y simpatizantes de todo el distrito. En este caso mencionado, la división del distrito y la presión sobre ejercida sobre el Gobierno por los dos aspirantes a candidato ministerial: Rizo y Loygorry, que este decidió mantenerse neutral. Entre la documentación archivada por Santiago Alba como Ministro de Gobernación durante aquella campaña se han encontrado casi un centenar de telegramas de apoyo a estas candidaturas por parte de los amigos de ambos aspirantes y organizaciones e instituciones locales ${ }^{38}$. Respecto del contenido, el mensaje va de la petición de apoyo: «Agradeceríamos muy de veras confirmaranse rumores Gobierno designando candidato Ibáñez Rizo, persona relevantes méritos personales», a la advertencia: «Partido liberal Tabernes Valldigna dispuesto votar candidatura Don Federico Loygorri».

38 En el AHN se han contabilizado ochenta y seis, entre los figuran telegramas de José Rubio, alcalde de Gandía; Domingo García, Alcalde de Alfamir; Faustino Carbo, Alcalde de Benirredra; José Moltó, Alcalde de Rotova; Rafael Martínez, alcalde Castellonet; Federico Mañez, exalcalde Beniopa; Joaquín Rosello, alcalde Villalonga; Bernardino Minana. Alcalde, Palma de Gandía; Salvador Montañer, exalcalde de Beniarjo; Silvestre Salert, exalcalde de Bellreguart; Pascual Morant, alcalde de la Alquería de la Condesa; Vicente Olaso, exalcalde de población no especificada; Fernando Poix, alcalde de Almoines; Manuel Penarrocha, exalcalde de Benipeixcar; José Sancho, alcalde Piles; Bautista Lorente, alcalde de Benifalla; Jesús Peiró, alcalde de Miramar; Salvador Part, alcalde Rafael Cofer; Hermelando Morera, Presidente círculo liberal Oliva; José Román, (en nombre de consignatarios de Gandía); Ricardo López, correligionario; Diego Morell, (en nombre de exportadores de frutas) y Vicente Ferrer, Presidente Circulo Liberal de Gandía. AHN, Leg.27-A, núm. 11. 
Sin embargo, y como muestra el estudio de la correspondencia de Antonio Maura durante las elecciones de 1903, el propio Gobierno dudaba y rectificaba muy a menudo en la elección de los candidatos adictos. La pugna entre tres aspirantes del Partido Conservador ocurrida en el distrito de Liria en 1903, ilustra sobre lo compleja que resultaba en ocasiones al Gobierno la elección del candidato ministerial. En estos comicios, debido a la oposición del aparato provincial del Partido Conservador a aceptar las directrices de Maura, se formaron en la provincia varias candidaturas paralelas. En Liria, frente a la candidatura «rebelde» del Marqués de Cáceres, se postularon dos candidatos seguidores de la línea oficial del partido, Juan J. Pardo y Prats. El primero, aspirante en principio designado por Maura como ministerial, tras observar movimientos en su contra por parte del Gobernador y del otro aspirante, le pidió al ministro mayor implicación a su favor a la vez que acusó de corrupto a su rival:

«No creo que haya nadie en el Gobierno que se atreva a discutirme el derecho de ser candidato adicto por Líria después de las poderosísimas razones que $\mathrm{V}$. aduzca en mi favor, pero si así no fuera, y contra lo que imponen la lógica y la costumbre de respetar derechos adquiridos a quien se opusiese a los míos...le ruego exija para mí el Distrito de Liria, distrito sumamente ministerial...en Villamarchante quieren destruir el Ayuntamiento...en Ribarroja buscan pretextos para procesar al Ayuntamiento; en Paterna tratan, (resucitando un antiquísimo expediente) que ciertos amigos que fueron de Rizo (exdiputado y notable de la zona) en que se apoya hoy Prats ocupen ciertas vacantes que hay en aquel Ayuntamiento.» ${ }^{39}$

Las acusaciones y críticas al aspirante rival se convirtieron en el mensaje más transmitido tanto por el aspirante como por sus amigos políticos que en su apoyo escribían al ministro ${ }^{40}$. Sin embargo, los consejos del Gobernador a favor de Prats convencieron a Maura para dejar a Pardo sin candidatura, algo de lo que el ministro se arrepintió poco después: «Hablando hoy con el Presidente del Consejo hemos visto que mucho dudamos de haber acertado en la designación del Sr. Prats por Liria, a la cual

\footnotetext{
39 Carta de Juan J. Pardo a Maura, 17 de enero de 1903. AM, Legajo 174, núm. 39.

40 «...dicho señor Prats, ha venido imperando y ejerciendo de cacique en este pueblo por espacio de muchos años no por interés político puesto que lo mismo ha votado a liberales que á conservadores para conservar el poder de sus paniaguados...». Carta del alcalde de Bétera a Maura, 12 de enero de 1903. AM, Legajo 174, núm. 39.
} 
me resigné yo sacrificando la aspiración del Sr. Pardo» ${ }^{41}$. Los resultados electorales demostraron al fin que los temores de Maura no eran infundados, ya que la candidatura de Prats no pudo superar los votos obtenidos por la del disidente. Este hecho da fe de la creciente necesidad por parte del Gobierno de escoger un candidato con gran fuerza en el distrito. Y explica de igual manera porque se van procurando cada vez con mayor frecuencia candidatos propios del distrito.

Esto último se palpó en las últimas elecciones del periodo. El Conde de Torrefiel en Albaida, Rubio Goula en Játiva, Izquierdo Alcalde en Liria y García-Berlanga Pardo en Requena, representaron el tipo de notables con control político sobre el distrito por el que se presentaban. En Alcira y Chiva, debido al apoyo que la izquierda tenía en las capitales del distrito, se eligieron a candidatos próximos a la izquierda dinástica más reformista. En Enguera y Sueca, se presentaron a los mismos candidatos que habían representado al distrito en los últimos años. Y en Gandía, el apoyo de los comités locales albistas a Melchor Román determinó que fuera este político y no el también albista Ibáñez Rico, el candidato del Gobierno. En definitiva, se observa cómo se va produciendo durante el periodo un trasvase de poder de decisión hacia los órganos locales del partido, lo que indica que la exigencia electoral es mucho mayor en 1923 que en 1890.

\section{Distritos propios}

Otra de las características del panorama electoral de los distritos uninominales en la España de la Restauración está relacionada con el nivel de influencia ejercida en ellos por los grandes notables, terratenientes o élites locales. Son los que se han venido llamando distritos de influencia propia, cacicatos estables o distritos propios. Denominaciones que sirven para describir aquellos distritos el grado de arraigo de un candidato o un grupo político sobre el distrito era suficiente para obtener el acta, independientemente de quien gobernara. Lo que se trata aquí de determinar, es de si la elección de los diputados con distrito propio estaba vinculada a la voluntad de los electores, o si por el contrario respondía a los manejos del candidato o la arbitrariedad gubernativa.

${ }^{41}$ Carta de Maura al Gobernador, 23 de marzo 1903. AM, Legajo 418/5. 
La historiografía apenas aporta datos sobre el alcance de los distritos propios en el encasillado. Pro, en su trabajo sobre manipulación electoral en España entre las legislaturas comprendidas entre 1890 a 1907, establece que su porcentaje sobre el total fue de poco más del cuarenta y dos por ciento. Tusell, en su estudio sobre el comportamiento electoral de Andalucía entre 1890 y 1923, sugiere que estos, a los que él llama cacicatos estables, llegaron en la provincia de Sevilla al cuarenta y cinco por ciento. Y Fernando del Rey y Javier Moreno, afirman, sin proporcionar porcentajes sobre el total, que en la región valenciana (Castellón, Valencia y Alicante) el número de distritos propios equivalía al de la media española; no tan alto como en Asturias, Baleares, La Rioja o Galicia, pero tampoco tan bajo como en Madrid o las provincias vasco-navarras ${ }^{42}$.

Con respecto al alcance de los distritos propios en la provincia de Valencia, al no existir ningún estudio cuantitativo previo se ha realizado una tabla basándose en los candidatos elegidos en un mismo distrito en tres o más elecciones. Como se observa en la tabla 4.3., los diputados de la provincia de Valencia con distrito propio «strictu sensu» lograron el 35,42\% de las actas rurales entre 1890 y $1923^{43}$. Si estos datos se comparan con los existentes para el resto del país, se verifica que el porcentaje de distritos rurales «propios» valencianos entre 1890 y 1907 es diez puntos menor que el de los sevillanos y otro tanto respecto a la media nacional ${ }^{44}$, algo que tiene su explicación, más que por la situación socio económica de la región, en las diferencias en cuanto a organización e implantación de partido. Divergencia que no solo afecta al porcentaje de distritos, sino también al comportamiento de los afectados.

Los diputados con distrito propio en Valencia presentan características diferentes unos de otros. Mención aparte merecen aquellos que lograron repetidamente el acta en un mismo distrito en función de los intereses locales, ya que para estos resulta inexacto hablar tanto de distrito propio como de cacicato estable, ya que dependían de los grupos económicos locales para su elección. Por tanto, si hay que adjudicar la propie-

42 Pro, 2000, p. 200, Tusell, 1970, p. 236, y Del Rey Reguillo, 1996, pp. 196-198. El porcentaje de Sevilla ha sido calculado tomando como variables los cincuenta y seis distritos afectados y las 128 elecciones entre 1890 y 1923.

4357 actas de las 224 totales.

${ }^{44} \mathrm{La}$ media nacional proporcionada, que incluye a los distritos urbanos de 1890 a 1907, es del $42.7 \%$. En el mismo periodo e incluyendo igualmente la circunscripción urbana, la media valenciana se sitúa en el $32,41 \%$. 
dad de distrito esta sería para estos colectivos y no para el portador del acta. Fidel García Berlanga y posteriormente su hijo, son el mejor ejemplo de ello. Tanto es así, que su designación dependía tanto del sindicato de viticultores (del cual García Berlanga era presidente), como de las juntas locales del partido demócrata. Un ejemplo de designación de la candidatura demócrata en Requena se encuentra en la asamblea convocada para tal efecto en mayo de 1919, a la que acudieron representantes del partido de Requena, Utiel, Ayora, Teresa de Cofrentes, Jalance, Millares, Venta del Moro, Cortes de Pallás, Fuenterrobles, Camporrobles, Caudete de las Fuentes, Villargordo del Cabriel, Zarra y Cofrentes ${ }^{45}$. En este caso, no solo es reseñable que la elección tuviera un apoyo masivo de los comités locales, sino el que prensa rival reconociera al diputado su derecho a presentarse en función de su labor en defensa del distrito.

«En relación a las gestiones de José García-Berlanga Pardo a favor de la economía vitivinícola del distrito en la legislatura que acababa; destacaron su negociación de la prórroga del convenio franco-español, su labor para el restablecimiento del impuesto de consumos sobre los alcoholes y la obtención de 50.000 pesetas del estado para el establecimiento de una red telefónica entre Requena y Utiel.» ${ }^{46}$

En este sentido, es importante reseñar como a partir de la reintroducción del sufragio universal masculino en 1890, se reproducirán situaciones que sugieren una incipiente opinión pública. La elección del candidato por parte de un sindicato local es una variante de asociacionismo que va a ir dificultando la asignación de candidatos por parte del gobierno. A ello habría que añadir la extensión de la prensa, que dificultó de algún modo el libre albedrío de los ministros a la hora de confeccionar el encasillado. Similares características al distrito de Requena tuvo el de Albaida, representado en Cortes por Manuel Iranzo. En ambos, las candidaturas representaban la voluntad de los intereses del distrito y no la personal, sin perjuicio de los beneficios económicos obtenidos por los negocios del propio

45 La asamblea, en El Pueblo, 13 de mayo de 1919.

46 Las Provincias, 14 de abril de 1919. Por su parte, los republicanos de la capital no dudan en aplaudir la designación de este candidato en función de la labor por el distrito por el que se quiere presentar: «ha sido un diputado completo que no solo logró conseguir caminos, escuelas o mejora de comunicaciones, sino que defendió en todo momento los intereses vitícolas y estuvo á la disposición y servicio de sus amigos y fue el más ferviente guardador de la independencia del distrito».El Pueblo, 13 de mayo de 1919. 
diputado a raíz de sus gestiones en la administración, ya que sus intereses coincidían con los de la mayoría de la población activa del distrito. Es precisamente por ello, por lo que incluso los republicanos de la capital apoyaran este tipo de candidaturas:

«Nuestro deseo sería que triunfase un candidato republicano; pero como esto no es posible en aquel distrito, nos parece acertada la designación del Sr. Iranzo, que ha realizado fecunda labor parlamentaria, como agrario con verdadera preparación técnica en tales materias. Nos satisface además que sean los distritos y no los Gobiernos los que nombre los representantes, Entre la repugnante é inmoral contradanza que vienen bailando en la corte los políticos valencianos para mendigar actas que solo debiera dar la voluntad del cuerpo electoral, el gesto de Albaida es digno de aplauso.» ${ }^{47}$

Otro tanto podría decirse del conservador José Montesinos Checa, diputado por Alcira y defensor de los intereses hortofrutícolas extendidos en aquella zona. Este diputado representó al diputado cuyo arraigo en el distrito no le vino dado, sino que se lo tuvo que ganar. Checa desarrolló su carrera profesional en Valencia, donde ejerció como juez de distrito a finales de siglo. Tras entrar en política se convirtió en alcalde de esta ciudad entre 1900 y 1901, y 1902 y 1903. Una vez elegido por Alcira (a la que llegó de la mano de De la Cierva en el encasillado de 1907), basó su política en la defensa de la economía local. Ello le permitió repetir escaño en cinco ocasiones, una de ellas a costa de romper el encasillado (1920). De su gestión quedó como hecho más destacable la obtención de la tarifa mínima para el transporte de fruta en los ferrocarriles del Norte y del Mediodía, hecho trascendental en la economía local, dirigida al cultivo y exportación de la naranja ${ }^{48}$.

En el resto de los distritos propios valencianos los diputados entremezclaban la defensa de los intereses locales con el uso de las redes clientelares a su servicio. El caso más característico fue el de Chelva, distrito controlado por la familia Gil Roger, cuya influencia en la política local se remonta a tiempos del Sexenio Revolucionario en los que Gil Roger y Duval obtuvo el acta de diputado. La influencia de esta familia se dejó notar en prácticamente todas las elecciones del distrito hasta 1914. Primero

47 El Pueblo, 22 de febrero de 1916.

48 AlCÁZAR, 1989, p. 260. 
con José Manteca (yerno de Gil Roger), después con Gil Roger Vázquez (hijo), y después con Crespo Azorín, amigo político de estos dos. La característica más destacada de este tipo de políticos era el control que ejercían sobre los ayuntamientos, los empleados de la administración y los jueces del distrito, que se unía al apoyo del que disponían del electorado. Precisamente este último le vino por el impulso del desarrollo local que él mismo potenció. En este sentido fomentó la Feria Agrícola y de Ganado - lo que incrementó las transacciones agropecuarias - promovió el comercio, e impulsó la plaza de toros de Chelva (cuyos terrenos el mismo cedió). Todo ello le permitió sobreponerse a la presión gubernamental, y a base de una combinación de clientelismo y votos verdad, poder derrotar a los candidatos encasillados.

En Gandía, Sinibaldo Gutiérrez Mas basó sus triunfos tanto en su influencia en la administración como en el apoyo que recibía de muchos de los electores del distrito. No hay que olvidar que además del control de los ayuntamientos de la zona de Gandía (heredado de Dimas Gutiérrez), contaba con gran apoyo electoral derivado del impulso desde el Congreso de la construcción del puerto de Gandía y de la línea de ferrocarril entre esta ciudad y Alcoy ${ }^{49}$.

En Enguera se observa la influencia del liberal Carlos Testor, tanto que su dominio sobre aquel distrito ha llegado a ser denominado como «Testorismo ${ }^{50}$. Esta hegemonía, que comenzó ya en las elecciones de 1881, vino determinada en un principio por los estrechos lazos que compartía con Ruiz de Capdepón, jefe provincial del partido. Su influencia en la capital española le valió para llegar a ser Director General de Agricultura, Industria y Comercio, Director General de Prisiones (en dos ocasiones), Comisario Regio de Seguros y finalmente Subsecretario del Ministro de Gracia y Justicia, cargos desde los que procuró interceder a favor de su distrito.

Más significativo fue el caso de Francisco Laiglesia, un destacado oficial de la Secretaría del Ministerio de Hacienda, que fue diputado consuetudinario por Játiva desde 1879 hasta 1914. Laiglesia representa al candidato cunero que acaba convirtiéndose en el diputado natural del distrito, y no precisamente por la arbitrariedad del Gobierno, sino por su identificación con él ${ }^{51}$. Su caso no fue el único. Tal y como señala Gabriel Maura,

\footnotetext{
49 YANINI, 1984b, p. 15.

50 Piqueras y Paniagua, 2006, p. 543.

51 El vínculo entre Játiva y Laiglesia, en Las Provincias, 9 de enero de 1891.
} 
era común en España que un cunero acabase haciéndose con el control del distrito al que por azares de la política le tocó en gracia en un encasillado: «los distritos rurales, ganosos de asegurarse un gestor de toda confianza, rechazaron más frecuentemente a los candidatos cuneros y, algunos de estos, llovidos un día desde el cielo oficial, arraigaron en la demarcación que les cupo en suerte representar» ${ }^{52}$.

La retirada política de Laiglesia por Játiva creó un vacío de poder en el distrito que dos grupos intentaron llenar: el de Ramón Castro y el de Rubio Goula. Fue este último quien, tras un acuerdo con Castro, se llevó finalmente el gato al agua, pero no sin antes haber competido muy duramente. No en vano, los abusos de las dos facciones en los comicios de 1916 y de 1919 motivaron la suspensión de ambos.

En definitiva, se concluye que los diputados con distrito propio debían su escaño a una combinación de control clientelar, apoyo de los representantes económicos del distrito y votos verdad. En este sentido, no se diferencian tanto los distritos propios de la provincia de Valencia con los «cacicatos estables» que analiza Tusell en Andalucía. Esto, que podría extrapolarse al resto de España, muestra que la figura de diputados con distrito propio, lejos de responder a la de un cacique o un encasillado dirigido por el Gobierno central que domina a su provecho el distrito, refleja la del respetado notable local cuya labor en pro del territorio al que representa en el Congreso le proporciona los suficientes méritos como para postularse y obtener de nuevo el apoyo de las fuerzas vivas y de los votantes.

Con respecto al análisis de los comicios donde ellos participaron, del cuadro anterior se pueden obtener varias conclusiones. Quizás la más significativa sea que todos y cada uno de los diputados que representaron al distrito al menos en tres ocasiones tuvieron que luchar en alguna ocasión para obtener el acta. La segunda es que ocho de los catorce diputados (57\% del total) perdieron las elecciones en alguna ocasión. Y la tercera, es que siete de cada catorce (la mitad) se presentaron como candidatos de oposición. Si se unen estos tres factores, es fácil concluir que los diputados con distrito propio no obtenían el acta sin esfuerzo. Por el contrario, los datos reflejan que estos candidatos tuvieron que luchar por sí mismos por su victoria, con o sin el apoyo del Gobierno.

52 Maura Gamazo, 1935, p. 108. 


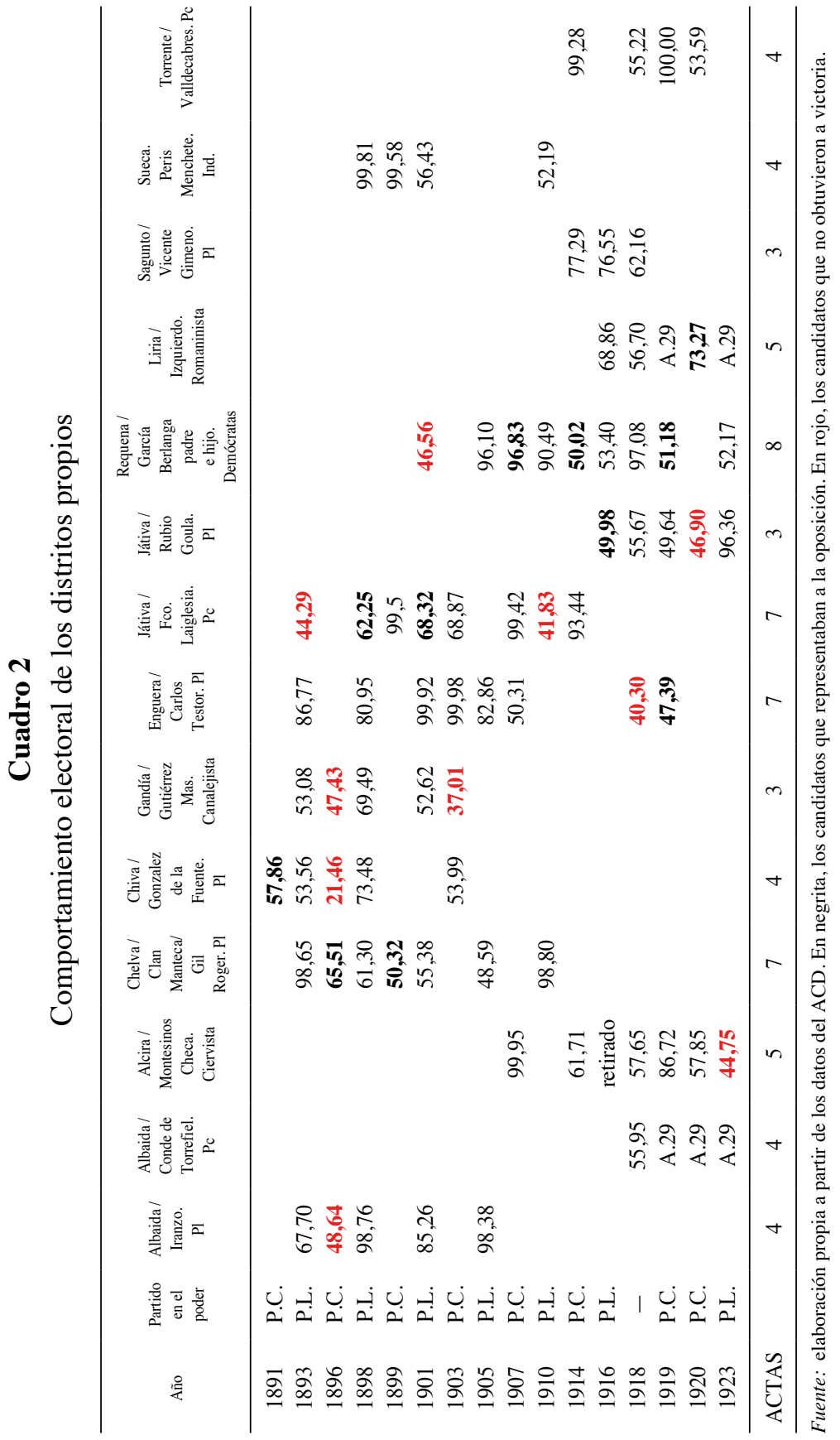




\section{Cuadro 3}

\section{Distritos propios}

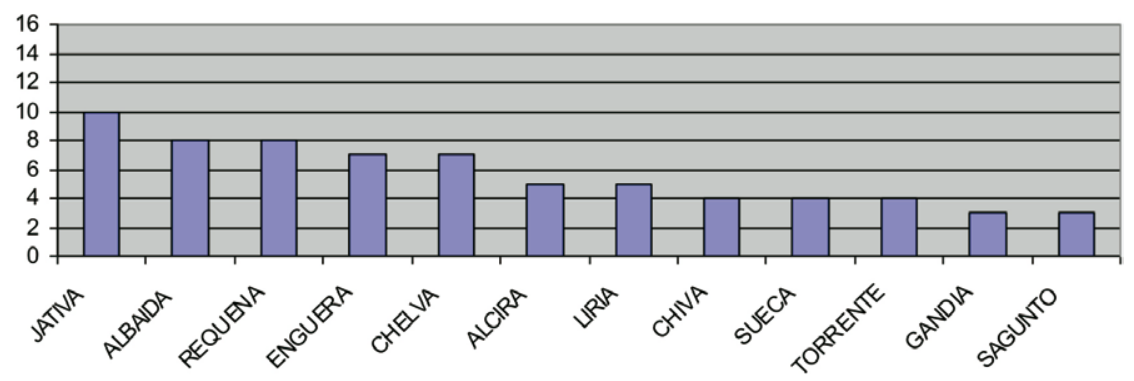

Fuente: elaboración propia a partir de los datos del ACD.

Al observar la influencia geográfica de los distritos estables, se extrae la conclusión de que fueron los distritos que carecían de notables hegemónicos, aquellos en donde el Gobernador podía confeccionar el encasillado a su medida sin presiones locales. Sagunto y Torrente respondían a este tipo de distritos. Por ello, eran más dados a las combinaciones y en última instancia al cunerismo, lo que por otro lado no quiere decir que fueran totalmente dóciles ${ }^{53}$.

${ }^{53}$ Esto entra en relación con la tesis de Tusell por la que la existencia de un «caciquismo estable» (como él los llama) es inversamente proporcional a su grado de docilidad y viceversa. TUSELL, 1970, p. 234. 


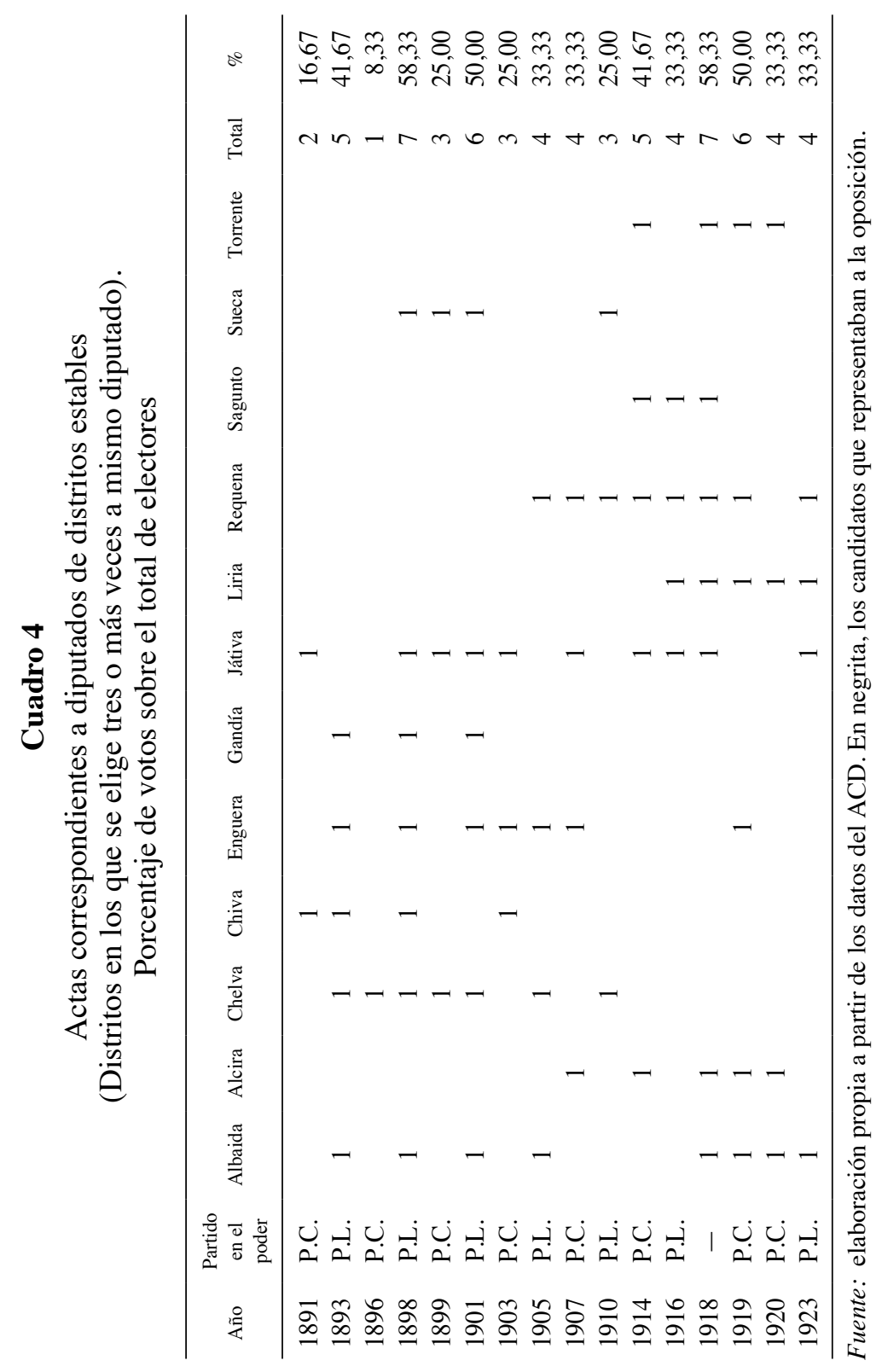




\section{Cuadro 5}

Evolución en el número de actas correspondientes a distritos rurales estables

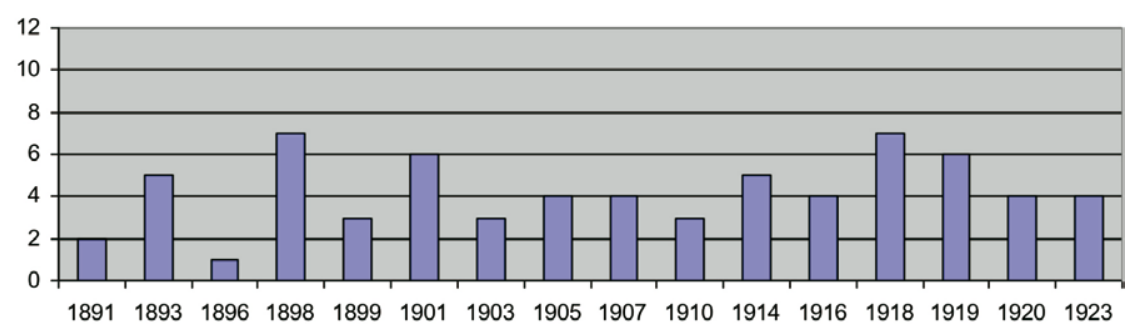

Fuente: elaboración propia a partir de los datos del ACD.

Quizás el hecho más significativo por cuanto tiene que ver con los distritos propios, es el consenso acerca del incremento adquirido por estos en los últimos años de la Restauración, momento en el que la crisis del sistema canovista permitía una mayor independencia en la actuación de los notables. No obstante, a través del análisis de los datos obtenidos se descubre que este incremento fue relativo, ya que las actas obtenidas en las últimas elecciones del periodo en estos «distritos propios» son menores que las obtenidas con anterioridad. De hecho, los resultados muestran que el impacto electoral de estos notables sobre sus distritos de influencia se mantuvo relativamente uniforme a durante gran parte de periodo. Lo que no quiere decir que no se produjera un creciente rechazo a las candidaturas de elementos sin relación con los intereses del propio distrito, como efectivamente aconteció. Fue este factor el que más dificultó los planes del Gobierno en los comicios, ya que los distritos rebeldes afectaban de manera negativa a la gobernabilidad del país por cuanto dificultaban el correcto funcionamiento del mecanismo del encasillado. En definitiva, el análisis de los distritos propios en Valencia evidencia que la elección de los diputados consuetudinarios estaba más vinculada a la voluntad de los electores y notables locales que a la arbitrariedad gubernativa. Esto lo evidencian hechos como el que todos ellos tuvieran que luchar por el acta, el que muchos de ellos perdieran en algún momento la elección, o el que la mitad se presentara alguna vez como candidato de oposición al encasillado. También resulta significativo que a día de hoy muchos de aquellos diputados naturales del distrito: Peris Mencheta, García Berlanga, Gil 
Roger o Gutiérrez Mas por mencionar los más característicos, sean personas apreciadas y recordadas en sus lugares de origen. Las placas con sus nombres en las calles de los pueblos a los que representaron no dejan de ser un testimonio de gratitud y recuerdo hacia ellos. Incluso a día de hoy, pasado ya más de un siglo, se siguen celebrando diferentes actos públicos que mantienen viva su memoria ${ }^{54}$.

\section{Conclusiones}

Del análisis de las fuentes primarias consultadas de la confección del encasillado en la provincia de Valencia se extraen varias conclusiones. En primer lugar, se evidencia que la confección del encasillado estaba encaminada a evitar la lucha. La designación de los candidatos ministeriales se vio mediatizada por las intenciones del resto de los grupos dinásticos del distrito. Y en caso de proclamarse candidaturas rebeldes, el Gobierno podía procurar hacerles desistir de concurrir a la lucha ofreciéndoles contrapartidas políticas. Con todo, no pudo evitar que la lucha, ya fuera por la pujanza en la región de las fuerzas antidinásticas como por la rebeldía de los grupos dinámicos locales, se produjera con relativa frecuencia. Por ello es por lo que se tuvo que pasar a escoger a los aspirantes por su peso electoral en el distrito. De lo contrario, el Gobierno se arriesgaba a la derrota. Quedaron prácticamente descartadas tanto las candidaturas cuneras, como aquellas que evidenciaban una influencia menor que la de su rival. La lucha, en definitiva, obligó a realizar una confección acorde con la voluntad de las fuerzas del distrito. En segundo lugar, se evidencia que, en contra de lo que ha venido siendo una opinión generalizada, no hubo, al menos en Valencia, un aumento de distritos propios. La cuantificación de los datos de este análisis muestra que la cantidad de candidatos encasillados con distrito propio en 1920 es de solo tres y en 1923 de cuatro, mientras que la mayor cantidad de encasillados de este tipo de dio en los comicios de 1898 y 1918. Por tanto, un candidato que quisiese presentarse por primera vez en algún distrito de la provincia no lo tenía más difícil al final

54 Por poner varios ejemplos, en Requena el teatro tiene el nombre de García Berlanga y en Utiel se realizó en 2014 una conferencia sobre el mencionado político, en Gandía existe la Calle Gutiérrez Mas, en Alcoy existe el Viaducto de Canalejas, en Sueca la Calle Peris Mencheta, en Onteniente (Albaida) la Calle Iranzo, en Chelva la Calle José Manteca, y en Villar del Arzobispo (Chelva) la Calle Gil Roger. 
del periodo que al principio, por la razón de que el porcentaje de distritos propios, que eran los más difíciles de lograr debido a la influencia electoral del diputado que los poseía, era prácticamente el mismo, y aun así era posible derrotar a uno de estos diputados. No en vano, en la provincia de Valencia se dio en este periodo hasta en once ocasiones

\section{Cuadro 6}

Encasillados con distrito propio

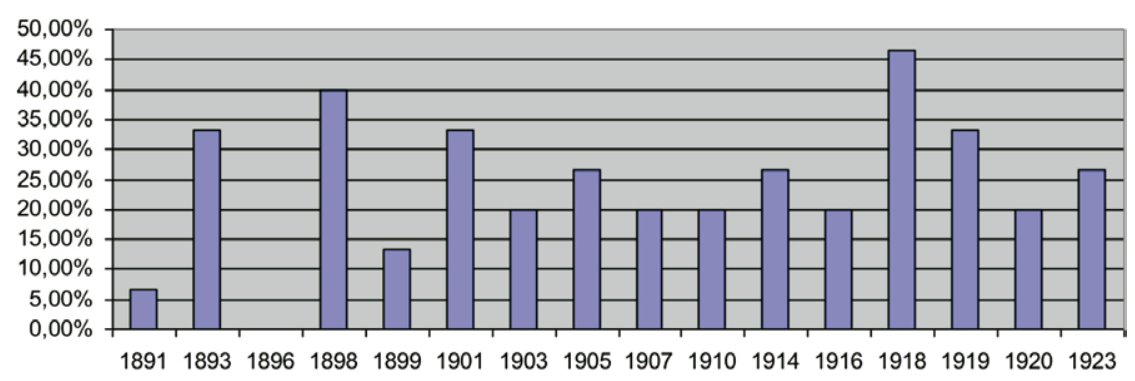

Fuente: elaboración propia a partir de los datos del ACD.

La tercera conclusión tiene que ver con los propios encasillados. El análisis de perfil político de los candidatos del Gobierno muestra unas características que distan mucho de las de los tan recurridos caciques. Al contrario, si se ignora el cliché, se observa que las personas seleccionadas para representar los distritos valencianos en el Congreso solían ser, salvo contadas excepciones, personalidades respetadas, cultas y relevantes en la sociedad de su tiempo ${ }^{55}$. Pero lo que es más importante, eran también aquellas en las que confluían los intereses legítimos de los grupos más influyentes del distrito.

Por último, es necesario señalar la evolución en la selección de los encasillados. Las fuentes no dejan lugar a dudas. Si durante los primeros años del periodo era el jefe provincial del partido el que escogía a personas de su círculo para representar a la provincia, durante el final del

55 Una aproximación a las personas que representaban a los distritos durante la Restauración, en TusELL, 1976, pp. 270-278. 
mismo el centro de decisión se trasladó a los distritos o a las organizaciones comarcales. Es más, en algunos de ellos la designación del candidato dependió de las propias juntas locales, lo que, se tradujo en una mayor independencia de los órganos municipales.

En definitiva, de todo lo expuesto anteriormente se evidencia que, pese a que la continuidad del encasillado retrasó la más que probable democratización de la Monarquía liberal, los procesos electorales durante este periodo fueron determinado que la confección del encasillado acabara dependiendo, en la mayoría de los casos, en el arraigo de los candidatos postulados en el distrito y no en el albedrío del ministro.

\section{Fuentes}

ARCHIVO HistóRICO NACIONAL, AHN.

ARChivo del Congreso de los Diputados, ACD.

ARChIVO MaURA, AM.

Real Academia de la Historia. Archivo Romanones.

\section{Bibliografía}

AlCÁZar, J., Temps d'avalots a País Valencià: (1914-1923), Diputació de València, Valencia, 1989.

Arranz, L., Silvela. Entre el liberalismo y el regeneracionismo, Gota a gota, Madrid, 2013.

Castillo, J.V., Política y elecciones en el distrito de Chiva (1891-1914), Instituto de Estudios Comarcales Hoya de Buñol-Chiva, Buñol, 1999.

DARDÉ, C., «Las elecciones como objeto de investigación», en La aceptación del adversario. Política y políticos de la Restauración, 1875-1900, Madrid, Biblioteca Nueva, 2003.

Forner, S. y García, M., Cuneros y caciques, Patronato Municipal del V Centenario de la Ciudad de Alicante, Alicante, 1990.

GARRIDO, A., «Sociología electoral de la Restauración: los estudios sobre el caciquismo», en G. RUEDA, Doce estudios de historiografía contemporánea, Santander, Universidad de Cantabria, 1991, pp. 169-182.

Genovés, A.V., El epistolario de Navarro Reverter con Cirilo Amorós, Ed. Fdo. Domenech, Valencia, 1981.

GonzÁlez HeRnández, M.J., El universo conservador de Antonio Maura: biografía y proyecto de Estado, Biblioteca Nueva, Madrid, 1997. 
GutiÉRreZ, R.A. y ZuRITA, R., «El encasillado en las elecciones de la España de la Restauración: Murcia y el País Valenciano en 1907», Historia Contemporánea, 22, 2001, pp. 307-342.

Marcos Del Olmo, M.C., Voluntad popular y urnas: elecciones en Castilla y León durante la Restauración y la Segunda República (1907-1936), Valladolid, Universidad de Valladolid, 1995.

Maura Gamazo, G., Recuerdos de mi vida, Aguilar, Madrid, 1935.

MORENO LuZÓN, J., «El poder público hecho cisco: clientelismo e instituciones políticas en la España de la Restauración», en RoBles EgEA (comp.), Política en penumbra: patronazgo y clientelismo políticos en la España contemporánea, Siglo veintiuno de España, Madrid, 1996, pp. 169-190.

Piqueras, J.A. y Paniagua, J., Diccionario biográfico de políticos valencianos 1810-2005, Institució Alfons el Magnànim, Valencia, 2006.

Pro RuIz, J., «Caciquismo y manipulación electoral en la España de la Restauración (1890-1907)», en Sánchez Mantero, En torno al «98»: España en el tránsito del siglo XIX y XX, Universidad de Huelva, Huelva, 2000, pp. 197208.

Rey Reguillo, F. (1998), «Las voces del antiparlamentarismo conservador», en Cabrera (dir.), Con luz y taquígrafos. El Parlamento en la Restauración (1913-1923), Taurus, Madrid, 1998, pp. 273-329.

CRUZ, S., Caciques y campesinos: poder político, modernización agraria y conflictividad rural en Granada, 1890-1923, Ediciones Libertarias, Madrid, 1994.

Romanones, Conde De, Biología de los Partidos Políticos, Ricardo Álvarez, Madrid, 1892.

SIN AUTOR, Discursos pronunciados en el banquete con que el Partido Conservador celebró el triunfo electoral obtenido en las elecciones municipales del 14 de noviembre de 1915, Imprenta hijos de J. García, Valencia, 1915.

TusELl, J., «Para la sociología política de la España contemporánea, el impacto de la Ley de 1907 en el comportamiento electoral», Hispania: revista española de historia, 116, 1970, pp. 571-632.

Tusell, J., Oligarquía y Caciquismo en Andalucía (1890-1923), Planeta, Barcelona, 1976.

VAREla ORTEGA, J., Los amigos políticos: partidos, elecciones y caciquismo en la Restauración: 1875/1900, Alianza Editorial, Madrid, 1977.

VARela Ortega, J. (dir.), El poder de la influencia: geografía del caciquismo en España (1875-1923), Centro de Estudios Políticos y Constitucionales, Madrid, 2001.

Veiga Alonso, X., «Anatomía del clientelismo político en la España liberal decimonónica: una realidad estructural», Hispania 59, No 202, 1999, pp. 637661 . 
YANINI, A., «Caciquisme electoral de la Restauració Alfonsina. el districte de Gandia entre 1876 y 1901», Ullal, 5, 1984, pp. 5-15.

YANINI, A., «Evolució del caciquisme: el districte electoral de sueca entre 18761901», Quaderns de Sueca, 6, 1984, pp 55-70.

\section{Financiación}

Esta investigación se inscribe en el marco del proyecto «Reformas Electorales y Competencia Política en el tránsito del liberalismo a la democracia» (Ref. HAR2015-68013-R MINECO-FEDER).

\section{Datos del autor}

Alejandro Martínez Relanzón es historiador. Licenciado en historia por la Universitat de València, completó su grado académico en la Georgia College \& State University (EEUU). Doctor con mención cum laude por la Universidad Rey Juan Carlos, ha centrado su tesis doctoral e investigación posterior en la democratización y el fraude electoral, tema sobre el que ha escrito un libro y varios artículos, publicados tanto en España como en el extranjero. También ha pronunciado conferencias sobre corrupción electoral durante la Restauración en diversos puntos de la geografía nacional y participado en proyectos de investigación a nivel nacional. En la actualidad realiza labores docentes en la Universidad Católica de Valencia y participa en un proyecto de investigación sobre reformas electorales y competencia política dirigido por el profesor de la Universidad Rey Juan Carlos, Roberto Villa. 